\title{
Physicochemical Basis for Formation of Renal Stones of Calcium Phosphate Origin: Calculation of the Degree of Saturation of Urine with Respect to Brushite
}

\author{
Charles Y. C. Pak \\ From the Endocrinology Branch, National Heart Institute, National Institutes \\ of Health, Bethesda, Maryland 20014
}

A B S T R A C T Brushite (CaHPO $\cdot 2 \mathrm{H}_{2} \mathrm{O}$ ) was considered to govern the formation of renal calculus of calcium phosphate origin. The degree of saturation of urine with respect to this phase was therefore calculated. This value was obtained from the ratio of the activity product of $\mathrm{Ca}^{++}$and $\mathrm{HPO}_{4}=\left(\mathrm{K}_{\mathrm{sp}}\right)$ before and after incubation of urine with brushite. The errors in the calculation of $K_{a p}$ were largely eliminated by this procedure.

The urine of patients with idiopathic hypercalciuria and recurrent calcium-containing renal calculi was supersaturated with respect to brushit largely because of the high urinary concentration of $\mathrm{Ca}^{++}$. The urine of normocalciuric subjects was undersaturated except at high urinary $\mathrm{pH}$. This technique of estimating the degree of saturation of urine should allow a quantitative assessment of the various therapeutic regimens recommended for patients with nephrolithiasis.

\section{INTRODUCTION}

The pathogenesis of renal stone of calcium phosphate origin represents dual processes of nidus formation and the subsequent development of the nidus into a stone. The formation of the nidus may be analagous to the first stage in physiologic calcification of bone in which a nucleus of calcium phosphate develops in an organic matrix (1-4). Alternatively, the nidus may form spontaneously by precipitation from a supersaturated urine (5-8). If this occurs, the organic phase may represent only secondary constituent of a stone, not etiologically important in its formation.

Once the crystal nidus has been established by either one of the two mechanisms, it develops into a renal

Received for publication 10 January 1969 and in revised form 11 April 1969. stone by precipitation or by the process of crystal growth. The high degree of internal structure usually found in the stone suggests an orderly addition of ions to the nidus by epistaxy (9) or under the influence of the interionic forces of the nidus rather than by simple precipitation.

A state of supersaturation of urine in terms of calcium and phosphate ions is probably essential for the development of a renal stone of calcium phosphate composition, irrespective of the mechanism for the nidus formation and the growth of the stone $(5,6,10)$. Furthermore, some degree of supersaturation is probably required for maintenance, since the stone may undergo partial dissolution in an undersaturated urine (11).

There is, however, a considerable disagreement as to whether the urine of patients with nephrolithiasis of calcium phosphate origin is supersaturated with respect to calcium and phosphate ions. This confusion has arisen from ( $a$ ) failure to calculate the solubility of calcium phosphate from ionic activities (12-16), and (b) disagreement regarding the specific calcium phosphate compound which governs the formation of the stone $(10,11,16,17)$.

In a previous communication, we considered brushite $\left(\mathrm{CaHPO}_{4} \cdot 2 \mathrm{H}_{2} \mathrm{O}\right)$ as the solid phase which is important in the pathogenesis of the calcium phosphate stone (11). It is the phase which is probably first formed from urine; its rate of hydrolysis into calcium phosphates of a higher calcium-to-phosphorus ratio is probably very slow at the normal acid $\mathrm{pH}$ of urine $(18,19)$. We therefore determined the solubility of brushite in urine as the activity product of $\mathrm{Ca}^{++}$and $\mathrm{HPO}_{4}^{-}$. From these studies it was possible to show that the urine specimens of patients with idiopathic hypercalciuria (20) were supersaturated with respect to brushite. The urine specimens from normocalciuric subjects were under-

1914 The Journal of Clinical Investigation Volume 481969 
TABLE I

Activity Coefficients of $\mathrm{HPO}_{4}^{-}, \mathrm{Ca}^{++}$, and $\chi$ at Varying Ionic Strengths $(\mu)^{*}$

\begin{tabular}{|c|c|c|c|c|c|c|c|c|}
\hline \multicolumn{9}{|c|}{$\begin{array}{c}x=7.182+\log \frac{\gamma \mathrm{HPO}_{4}^{-}}{\gamma \mathrm{B}_{2} \mathrm{PO}_{4}^{-}} \\
\text {(equation 5) }\end{array}$} \\
\hline$\mu$ & $\gamma \mathrm{K} \mathrm{H}_{2} \mathrm{PO}$ & $\gamma \mathrm{H}_{2} \mathrm{PO}_{4}^{-}$ & $\gamma \mathrm{cl}^{-}$ & $2 A \sqrt{\mu}$ & $B \mu$ & $\gamma \mathrm{HPO}_{4}^{-}$ & $\gamma \mathrm{Cs}^{++}$ & $x$ \\
\hline 0.010 & 0.896 & 0.889 & 0.902 & 0.103 & 0.008 & 0.644 & 0.672 & 7.042 \\
\hline 0.025 & 0.844 & 0.832 & 0.856 & 0.163 & 0.020 & 0.512 & 0.564 & 6.971 \\
\hline 0.050 & 0.792 & 0.768 & 0.817 & 0.231 & 0.040 & 0.404 & 0.478 & 6.903 \\
\hline 0.075 & 0.756 & 0.723 & 0.790 & 0.283 & 0.060 & 0.342 & 0.430 & 6.857 \\
\hline 0.100 & 0.731 & 0.697 & 0.767 & 0.326 & 0.080 & 0.303 & 0.396 & 6.821 \\
\hline 0.125 & 0.708 & 0.675 & 0.743 & 0.365 & 0.100 & 0.273 & 0.367 & 6.788 \\
\hline 0.150 & 0.685 & 0.638 & 0.736 & 0.400 & 0.120 & 0.246 & 0.353 & 6.767 \\
\hline 0.165 & - & - & - & - & - & 0.229 & 0.343 & - \\
\hline 0.200 & 0.653 & 0.595 & 0.717 & 0.462 & 0.160 & 0.213 & 0.323 & 6.736 \\
\hline 0.300 & 0.602 & 0.529 & 0.685 & 0.565 & 0.240 & 0.171 & 0.287 & 6.693 \\
\hline
\end{tabular}

* Terms necessary in their calculation are also presented.

saturated except at a high urinary $\mathrm{pH}$; at a $\mathrm{pH}$ above 6.5 most of the specimens (14 of 18) were supersaturated. In this communication, the method for the calculation of this activity product and for the estimation of the degree of saturation of urine with respect to brushite will be described in detail.

\section{METHODS}

The activity product of brushite $\left(K_{s p}\right)$ may be described by the equation:

$$
\mathrm{K}_{\mathrm{sp}}=\mathrm{aCa}^{++} \cdot \mathrm{a}_{\mathrm{HPO}_{4}}{ }^{-}=\left[\mathrm{Ca}^{++}\right] \gamma_{\mathrm{Ca}^{++}} \cdot\left[\mathrm{HPO}_{4}{ }^{-}\right] \gamma_{\mathrm{HPO}_{4}-}
$$

where $a$ is the activity (21), the brackets [ ] denote molar concentration, and $\gamma$ represents activity coefficient. The problem in calculating $\mathrm{K}_{\mathrm{sp}}$ of urine resolves into $(a)$ the estimation of $\left[\mathrm{HPO}_{4}^{-}\right]$from the concentration of total orthophosphate $[\mathrm{P}]$ in urine, (b) estimation of ionic strength, $\mu$, by the method to be described in Methods, section $\mathrm{D}$, and $(c)$ calculation of the activity coefficients for $\mathrm{Ca}^{++}$and $\mathrm{HPO}_{4}^{-}$ at the ionic strength of the urine. The calculation of $K_{8 p}$ requires the knowledge of $\mu$, since both activity coefficients of $\mathrm{Ca}^{++}$and $\mathrm{HPO}_{4}^{-}$and the degree of dissociation of dihydrogen phosphate are dependent on $\mu$, as will be shown.

A. Estimation of $\mathrm{HPO}_{4}^{-}$. For the reaction of $\mathrm{H}_{2} \mathrm{PO}_{4}^{-} \rightleftharpoons \mathrm{H}^{+}$

$+\mathrm{HPO}_{4}^{-}$, the dissociation constant $\left(K_{2}\right)$ is represented by:

$$
K_{2}=\frac{\alpha_{\mathrm{HPO}_{4}}^{-\cdot} \cdot \alpha_{\mathrm{H}^{+}}}{\alpha_{\mathrm{H}_{2} \mathrm{PO}_{4}^{-}}^{-}}=\frac{\gamma_{\mathrm{HPO}_{4}^{-}}^{-}}{\gamma_{\mathrm{H}_{2} \mathrm{PO}_{4}^{-}}} \cdot \frac{\left[\mathrm{HPO}_{4}^{-}\right]}{\left[\mathrm{H}_{2} \mathrm{PO}_{4}^{-}\right]} \cdot \alpha_{\mathrm{H}^{+}}
$$

In logarithmic form, equation 2 becomes:

$$
\mathrm{pH}=\mathrm{p} K_{2}+\log \frac{\gamma_{\mathrm{HPO}_{4}^{-}}}{\gamma_{\mathrm{H}_{2} \mathrm{PO}_{4}^{-}}}+\log \frac{\left[\mathrm{HPO}_{4}^{-}\right]}{\left[\mathrm{H}_{2} \mathrm{PO}_{4}^{-}\right]}
$$

Given urinary $\mathrm{pH}$ and the $\mathrm{p} K_{2}$ for the equilibrium of 7.182 (22), the ratio of $\left[\mathrm{HPO}_{4}{ }^{-}\right]$to $\left[\mathrm{H}_{2} \mathrm{PO}_{4}^{-}\right]$can be calculated if the activity coefficients are known.

where

$$
\frac{\left[\mathrm{HPO}_{4}^{-}\right]}{\left[\mathrm{H}_{2} \mathrm{PO}_{4}^{-}\right]}=\operatorname{antilog}(\mathrm{pH}-x)
$$

$$
x=\mathrm{p} K_{2}+\log \left[\gamma_{\mathrm{HPO}_{4}}-/ \gamma_{\mathrm{H}_{2} \mathrm{PO}_{4}}-\right]
$$

$\chi$ was calculated at various ionic strengths of urine by means of the activity coefficients for $\mathrm{HPO}_{4}^{-}$and $\mathrm{H}_{2} \mathrm{PO}_{4}^{-}$which were determined by the method to be described (Table I, Fig. 1).

When $x$ is known, [HPO ${ }_{4}^{-}$] may be calculated from [P]. Since in the $\mathrm{pH}$ range of urine the only ionic species of phosphate present in significant concentrations are $\mathrm{H}_{2} \mathrm{PO}_{4}^{-}$and $\mathrm{HPO}_{4}^{-}$, we assume:

$$
[\mathrm{P}]=\left[\mathrm{H}_{2} \mathrm{PO}_{4}^{-}\right]+\left[\mathrm{HPO}_{4}^{-}\right]
$$

where $[\mathrm{P}]$ is the molar concentration of total phosphate as determined by chemical analysis. $\left[\mathrm{HPO}_{4}^{-}\right]$can therefore be obtained from the equation:

$$
\left[\mathrm{HPO}_{4}^{-}\right]=[\mathrm{P}] \frac{\{\operatorname{antilog}(\mathrm{pH}-\chi)\}}{1+\{\operatorname{antilog}(\mathrm{pH}-x)\}}
$$

B. Calculation of the activity coefficient of $\mathrm{Ca}^{++} . \gamma_{\mathrm{Cs}^{++}}$was calculated from an extension of the Debye-Hückel limiting law, which shows dependence of $\gamma$ on ionic strength $(\mu)$ :

$$
-\log \gamma=\frac{A z^{2} \sqrt{\mu}}{1+B b \sqrt{\mu}}
$$

where $z$ is the valence, $b$ the effective ionic radius in Angstroms, and $A$ and $B$ are temperature-dependent constants. $\gamma_{\mathrm{Ca}^{+}}{ }^{++}$was calculated for various ionic strengths with the values for $\mathrm{b}, A$, and $B$ given by Moreno and associates (22) and with those given by Frankenthal (23). Values for $\gamma_{\mathrm{Ca}^{++}}$obtained with the two sets of values were slightly different; an average of the two values for $\gamma_{\mathrm{Ca}^{++}}$was employed in this study (Table I, Fig. 1).

C. Calculation of the activity coefficient of $\mathrm{HPO}_{4}^{-} \cdot \gamma_{\mathrm{HPO}_{4}}^{-}$ could be obtained from equation 8 by substitution of appropriate values for $\mathrm{b}, A$, and $B(22,24)$. However, we chose to employ a more direct method, described by Levinskas (25), for estimating $\gamma_{\mathrm{BPO}}^{-}$-

Nims (26) has derived the following equation from the Debye-Hückel theory:

$$
\log \left[\frac{\gamma_{\mathrm{Cl}^{-} \cdot \gamma_{\mathrm{H}_{2} \mathrm{PO}_{4}^{-}}}}{\gamma_{\mathrm{HPO}_{4}}^{-}}\right]=2 A \sqrt{\mu}-B_{\mu}
$$

On rearrangement, equation 9 leads to:

$$
\log \gamma_{\mathrm{HPO}_{4}^{-}}^{-}=\log \gamma_{\mathrm{Cl}^{-}}+\log \gamma_{\mathrm{H}_{2} \mathrm{PO}_{4}^{-}}-2 A \sqrt{\mu}+B_{\mu}
$$




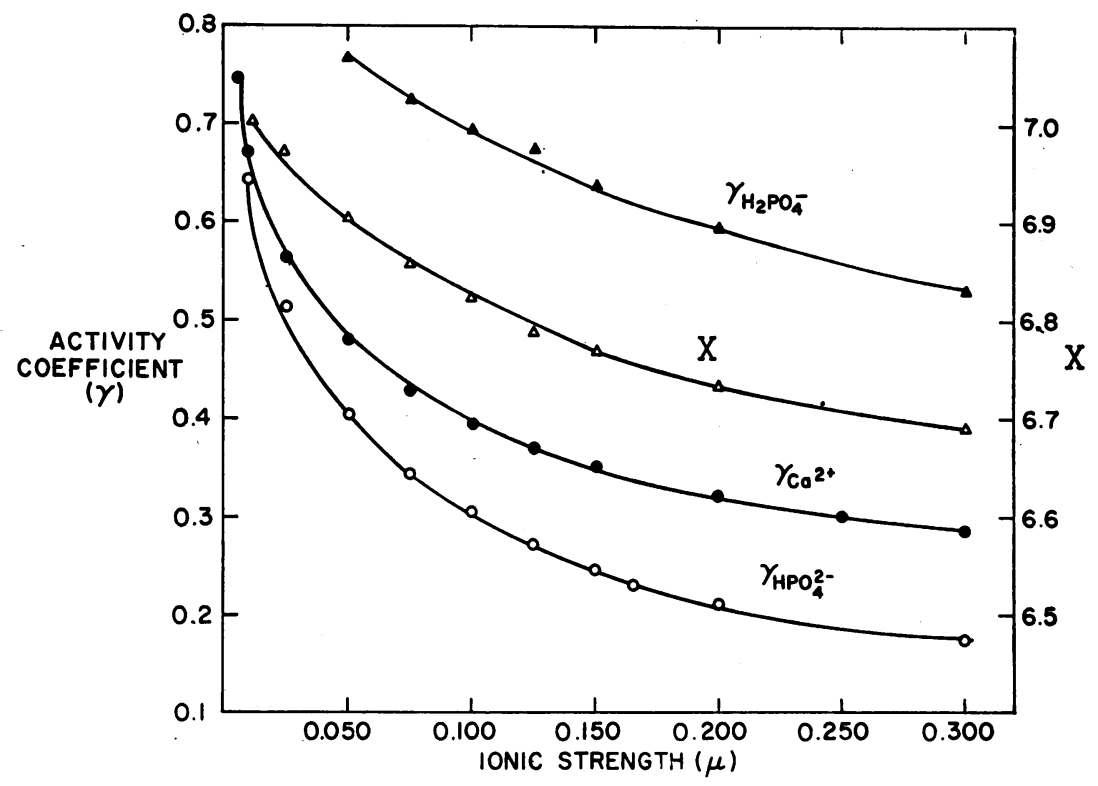

FIGURE 1 Activity coefficients of $\mathrm{Ca}^{++}, \mathrm{HPO}_{4}{ }^{-}, \mathrm{H}_{2} \mathrm{PO}_{4}^{-}$, and $\chi$ (equation 5) at varying ionic strengths.

$\gamma_{\mathrm{HPO}^{-}}$- was calculated from the terms of the right side of equation 10. Values of $A$ and $B$ were determined experimentally by Nims (26) from electromotive force measurements of cells without liquid junction. $\gamma_{\mathrm{Cl}^{-}}$was assumed to be equal to $\gamma_{\mathbf{K C l}}(27)$; it was therefore obtained from the values of $\gamma \mathrm{KCl}$ presented by Harned and Owen (28). $\gamma_{\mathrm{H}_{2} \mathrm{PO}_{4}^{-} \text {was }}$ calculated from $\gamma \mathrm{KH}_{2} \mathrm{PO}_{4}$ from the following equation:

$$
\gamma_{\mathrm{H}_{2} \mathrm{PO}_{4}^{-}}^{-}=\frac{\gamma^{2} \mathrm{KH}_{2} \mathrm{PO}_{4}}{\gamma \mathrm{K}^{+}}
$$

$\gamma_{\mathrm{KH}_{2} \mathrm{PO}_{4}}$ was obtained from the data of Harned and Owen (28) or was calculated according to Stokes (29). $\gamma_{K^{+}}$was assumed to be equal to $\gamma \mathrm{KCl}(27)$. Table I presents the values for all the terms of equation 10 at various ionic strengths.

D. Calculation of ionic strength $(\mu)$ of urine. $\gamma_{\mathrm{Ca}^{++}}{ }^{++}$and $\gamma_{\mathrm{HPO}_{4}}{ }^{-}$are dependent on $\mu$ (equation 8). Further, since $x$ varies with ionic strength (Table I, Fig. 1), $\left[\mathrm{HPO}_{4}^{-}\right]$is also dependent on $\mu$ (equation 7 ). The $\mu$ value for 12 urine specimens was calculated from the following equation:

$$
\begin{aligned}
\mu=\frac{1}{2}\left\{\left[\mathrm{Na}^{+}\right]+\left[\mathrm{K}^{+}\right]+\left[\mathrm{NH}_{4}{ }^{+}\right]+4\left[\mathrm{Ca}^{++}\right]\right. \\
+4\left[\mathrm{Mg}^{++}\right]+\left[\mathrm{Cl}^{-}\right]+\left[\mathrm{H}_{2} \mathrm{PO}_{4}^{-}\right] \\
\left.+4\left[\mathrm{HPO}_{4}^{-}\right]+4\left[\mathrm{SO}_{4}^{-}\right]+\left[\mathrm{A}^{-}\right]\right\}
\end{aligned}
$$

where $\left[\mathrm{HPO}_{4}^{-}\right]$and $\left[\mathrm{H}_{2} \mathrm{PO}_{4}^{-}\right]$were calculated from $[\mathrm{P}]$ according to the method described in section $A$, and $\left[\mathrm{A}^{-}\right]$ represented anion deficit, calculated as the concentration of univalent anions required to satisfy the requirement of electrical neutrality. The concentrations of citrate, pyrophosphate, and oxalate were not included in this calculation. Nevertheless, equation 12 probably gives a reasonably accurate estimate of $\mu$, since these anions are normally present in low concentrations in urine.

The value of $\mu$ calculated from equation 12 was compared with that obtained from cation composition alone given as

$\mu_{\text {eat }}=\left[\mathrm{Na}^{+}\right]+\left[\mathrm{K}^{+}\right]+\left[\mathrm{NH}_{4}\right]$

$$
+4\left[\mathrm{Ca}^{++}\right]+4\left[\mathrm{Mg}^{++}\right]
$$

The ratio of $\mu$ to $\mu_{\text {cat }}$ was $1.056 \pm 0.002$ (SEM) (Table II).
A good correlation between $\mu$ and $\mu_{\text {cat }}$ was demonstrated despite wide variation in $\mathrm{pH}$ and $[\mathrm{P}]$.

$$
\mu=1.056 \mu_{\text {cat }}
$$

Equation 14 was usually employed to estimate the $\mu$ of urine

$E$. Calculation of activity product of brushite $\left(K_{\mathrm{sp}}\right)$. Equation 1 may now be solved for $\mathrm{K}_{s \mathrm{p}}$. Values for $\left[\mathrm{Ca}^{++}\right]$were obtained directly by chemical analysis. ${ }^{1}$ Values of $\gamma_{\mathrm{Ca}^{++}}$and $\gamma_{\mathrm{HPO}}{ }^{-}$ were derived from Fig. 1 , based on the value of $\mu$ calculated according to equation 13 or 14 . Values of $\left[\mathrm{HPO}_{4}{ }^{-}\right]$were determined from equation 7 , based upon the value of $[P]$ obtained directly by chemical analysis, and the value of $x$ was obtained from Fig. 1.

$\mathrm{K}_{\mathrm{ap}}$ obtained by this method was slightly lower than the activity product of brushite calculated according to Moreno and associates ${ }^{2}(22)$.

Sample calculation. Given $\left[\mathrm{Ca}^{++}\right]=0.002$ mole/liter, $[\mathrm{P}]=0.01$ mole/liter, $\mathrm{pH}=6.767,\left[\mathrm{Na}^{+}\right]=0.097 \mathrm{~mole} /$ liter, $\left[\mathrm{K}^{+}\right]=0.013 \mathrm{~mole} / \mathrm{liter},\left[\mathrm{NH}_{4}{ }^{+}\right]=0.016 \mathrm{~mole} / \mathrm{liter}$, and $\left[\mathrm{Mg}^{++}\right]=0.002$ mole/liter.

From equations 13 and $14, \mu$ is $0.150 . \gamma_{\mathrm{Ca}^{++}}$is 0.353 and $\gamma_{\mathrm{HPO}_{4}}{ }^{-}$is 0.264 at this ionic strength (Fig. 1). Since $\chi$ is given as 6.767 (Fig. 1), antilog $(\mathrm{pH}-\chi)$ is 1 (equation 4). [ $\left.\mathrm{HPO}_{4}{ }^{-}\right]$ is therefore equal to 0.005 mole/liter (equation 7).

$$
\begin{aligned}
\mathrm{K}_{\mathrm{sp}}=\gamma_{\mathrm{Ca}^{++}} \cdot\left[\mathrm{Ca}^{++}\right] \cdot \gamma_{\mathrm{HPO}_{4}} \cdot \cdot\left[\mathrm{HPO}_{4}{ }^{-}\right] \\
\\
=(0.353)(0.002)(0.264)(0.005)=9.32 \times 10^{-7} .
\end{aligned}
$$

$F$. Estimation of the degree of saturation of urine with respect to brushite; correction of errors in the calculation of $K_{\mathrm{sp}} . \mathrm{K}_{\mathrm{sp}}$ of urine calculated by this method probably represents an overestimation of the solubility of brushite because of the forma-

1 All of the calcium determined chemically (31) was considered to be in the ionized form, although some of it is complexed. This simplication is justified since it was corrected in the subsequent calculation of the degree of saturation of urine, as will be shown in Methods, section F.

Pak, C. Y. C. Data in preparation. 
TABLE II

Estimation of Ionic Strength of Urine from Urinary Electrolyte Composition

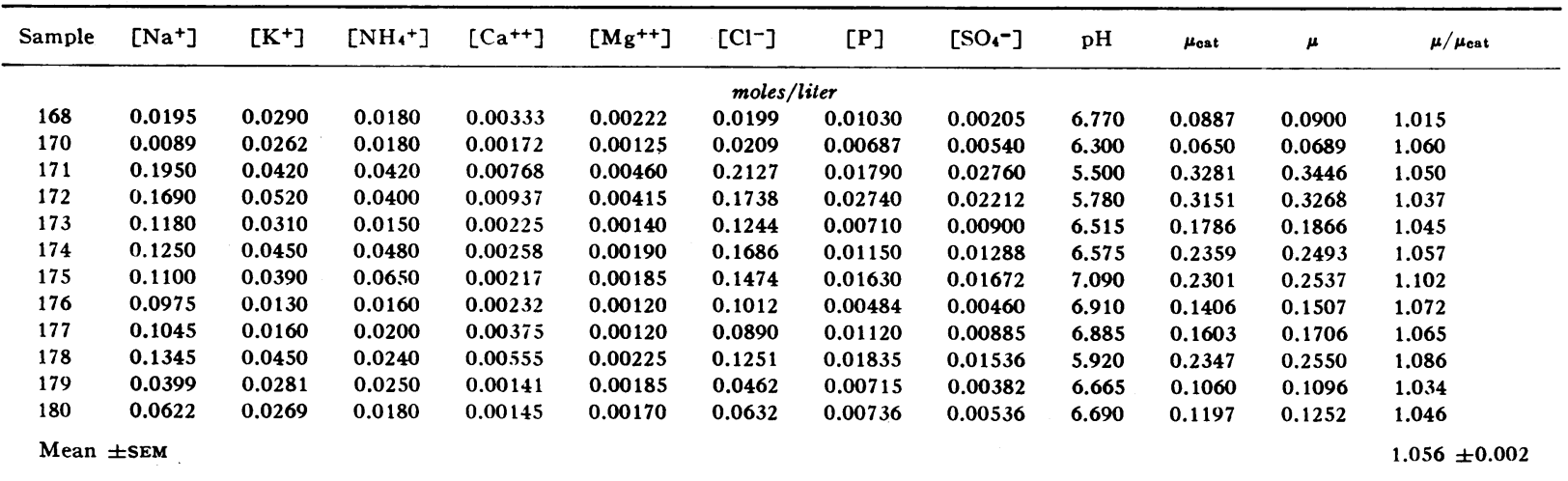

Ionic strength calculated from all ions listed $(\mu)$ is compared with that calculated from cations alone $\left(\mu_{\text {cat }}\right)$.

tion of complexes between $\mathrm{Ca}^{++}$and $\mathrm{HPO}_{4}{ }^{-}$and various ligands in urine. In our analysis, calcium and phosphate in urine were considered to exist as free ions, although they are probably partially complexed. Important ligands for $\mathrm{Ca}^{++}$ include citrate, oxalate, $\mathrm{H}_{2} \mathrm{PO}_{4}{ }^{-}$, and $\mathrm{SO}_{4}{ }^{-}$; ligands for $\mathrm{HPO}_{4}{ }^{-}$ are probably $\mathrm{Mg}^{++}, \mathrm{Na}^{+}$, and $\mathrm{K}^{+}(17)$. The amount of calcium and phosphate ions which are complexed, and not contributing to the activity product, could be calculated from the stability constants for the various complexes (17). However, such a calculation represents a formidable task because of the numerous possible complexes, uncertainty regarding the accuracy of stability constants, and the need for determining experimentally all the ligands in urine.

We have therefore devised a simplified approach (11) which largely corrects the errors resulting from complex formation, and which removes uncertainties in the calculation of the complexed species of calcium and phosphate from the stability constants. This was achieved by calculating $\mathrm{K}_{\mathrm{sp}}$ of the supernatant urine after it had been incubated with brushite. The activity product of the urine supernatant $\left(K_{s p, f}\right)$ was then compared with that of the original urine $\left(K_{s p, i}\right)$. Activity product ratio $\left(\mathrm{K}_{\mathrm{sp}, \mathrm{i}} / \mathrm{K}_{\mathrm{sp}, \mathrm{f}}\right)$ represents the degree of saturation of urine, where the value of 1 indicates saturation, a value greater than 1, supersaturation, a value less than 1 , undersaturation. The errors attendant upon our method of calculation of activity product were largely cancelled out by this technique since they probably contributed to both $K_{\mathrm{sp} \text {, }}$ and $K_{s p, f}$, as may be appreciated from the following considerations.

The combination of $\mathrm{Ca}^{++}$or $\mathrm{HPO}_{4}^{-}(\mathrm{M})$ by ligand (A) to form a complex (MA) may be illustrated by the following equation:

$$
[\mathrm{MA}]=K_{a}[\mathrm{M}][\mathrm{A}] \cdot \gamma_{\mathrm{M}} \cdot \gamma_{\mathrm{A}}
$$

where $K_{a}$ is the stability constant. Since the $\mu$ of urine is not significantly altered upon incubation with brushite, $\gamma_{M}$ and $\gamma_{\mathbf{A}}$ remain essentially constant. Furthermore, [A] probably does not change significantly with incubation. In our studies, there was no significant change in $\left[\mathrm{Mg}^{++}\right],\left[\mathrm{Na}^{+}\right]$, and $\left[\mathrm{K}^{+}\right]$ upon incubation with brushite. Concentrations of sulfate, citrate, and oxalate, measured in selected urines, also did not change. On the other hand, $\left[\mathrm{H}_{2} \mathrm{PO}_{4}^{-}\right]$was altered slightly with incubation as shown by a small change in [P] (Table III). However, $\mathrm{H}_{2} \mathrm{PO}_{4}^{-}$is probably not an important ligand in urine, since we were not able to demonstrate a significant formation of $\mathrm{CaH}_{2} \mathrm{PO}_{4}^{+}$under our experimental conditions. ${ }^{2}$
[MA] is therefore directly proportional to $[\mathrm{M}]$, since other terms in equation 15 remain essentially constant. In other words, a fixed fraction of the total $\mathrm{Ca}^{++}$or $\mathrm{HPO}_{4}^{-}$is complexed regardless of the changes in $\left[\mathrm{Ca}^{++}\right]$or $\left[\mathrm{HPO}_{4}{ }^{-}\right]$resulting from incubation with brushite. This "bound fraction" cancels out in the calculation of the activity product ratio $\left(\mathrm{K}_{\mathrm{sp}, \mathrm{i}} / \mathrm{K}_{\mathrm{sp}, t}\right)$. Errors in the calculation of the activity product of brushite, arising from complex formation, are thus removed. This procedure of estimating the degree of saturation of urine should be equivalent to obtaining the ratio of the true activity product of urine (corrected for complex formation) with the theoretical activity product of brushite $\left(\mathrm{K}_{\mathrm{sp}, \mathrm{th}}\right)$ of $2.68 \times 10^{-7}$ (18).

It should be emphasized that other possible errors of our calculation of $\mathrm{K}_{\mathrm{sp}}$, such as that occuring during the calculation of $\mu$, or that arising from the particular method employed for the calculation of $K_{s p}$, are also largely corrected by this procedure.

TABLE III

Influence of Incubation with Brushite on the Urinary Composition of Supersaturated Urines and Undersaturated Urines

\begin{tabular}{lcc}
\hline & $\begin{array}{c}\text { Supersaturated } \\
\text { urines }\end{array}$ & $\begin{array}{c}\text { Undersaturated } \\
\text { urines }\end{array}$ \\
\hline$\left[\mathrm{Ca}^{++}\right]_{\mathrm{i}}$, mmoles/liter & $2.94 \pm 0.36$ & $1.20 \pm 0.11$ \\
{$\left[\mathrm{Ca}^{++}\right]_{\mathrm{f}, \text { mmoles } / \text { liter }}$} & $1.86 \pm 0.21$ & $2.02 \pm 0.20$ \\
{$[\mathrm{P}]_{\mathrm{i}, \text { mmoles } / \text { liter }}$} & $12.26 \pm 1.42$ & $9.91 \pm 0.88$ \\
{$[\mathrm{P}]_{\mathrm{f}, \text { mmoles } / \text { liter }}$} & $11.05 \pm 1.43$ & $10.97 \pm 0.82$ \\
$\mathrm{pH}_{\mathrm{i}}$ & $6.526 \pm 0.077$ & $6.054 \pm 0.082$ \\
$\mathrm{pH}_{\mathrm{f}}$ & $6.467 \pm 0.075$ & $6.264 \pm 0.091$ \\
$\mathrm{~K}_{\mathbf{s p , i}}\left(10^{-7}\right)$ & $8.616 \pm 0.844$ & $1.817 \pm 0.247$ \\
$\mathrm{~K}_{\mathrm{sp}, \mathrm{f}}\left(10^{-7}\right)$ & $3.530 \pm 0.126$ & $3.706 \pm 0.277$ \\
$\mathrm{~K}_{\mathrm{sp}, \mathrm{i}} / \mathrm{K}_{\mathrm{sp}, \mathrm{f}}$ & 2.441 & 0450
\end{tabular}

Subscript $\mathrm{i}$ indicates before incubation, $\mathrm{f}$ after incubation. Values are given as mean \pm SEM. Note that before incubation, calcium concentration $\left[\mathrm{Ca}^{++}\right]_{i}$ and activity product $\left(\mathrm{K}_{\mathrm{sp}, \mathrm{i}}\right)$ were significantly higher in the supersaturated than in the undersaturated urines. After incubation, $\left[\mathrm{Ca}^{++}\right]_{\mathrm{f}}$ and $\mathrm{K}_{\mathbf{s p}, \mathrm{f}}$ were similar in the two groups. 
TABLE IV

Comparison of Urines from Three Groups of Subjects

\begin{tabular}{|c|c|c|c|c|c|c|}
\hline \multirow{6}{*}{$\begin{array}{l}\mathrm{Ca}, \mathrm{mg}_{\mathrm{g}}^{\prime} \text { day } \\
{\left[\mathrm{Ca}^{++}\right], \text {mmoles/liter }} \\
\mathrm{P}, \mathrm{mg}_{\text {gay }} \\
{[\mathrm{P}], \text { mmoles } / \text { liter }} \\
\mathrm{TV}, \text { ml/day }\end{array}$} & \multicolumn{2}{|c|}{ Group I } & \multicolumn{2}{|c|}{ Group II } & \multicolumn{2}{|c|}{ Group III } \\
\hline & 292 & \pm 9 & 136 & \pm 3 & 107 & \\
\hline & 3.41 & \pm 0.35 & 1.62 & \pm 0.09 & 1.24 & \pm 0.12 \\
\hline & 763 & \pm 34 & 580 & \pm 32 & 660 & \pm 50 \\
\hline & 11.50 & \pm 1.47 & 8.92 & \pm 0.75 & 9.87 & \pm 0.81 \\
\hline & 2140 & \pm 137 & 2099 & \pm 137 & 2157 & \pm 194 \\
\hline$\mu$ & 190.8 & \pm 11.0 & 151.8 & \pm 9.1 & 148.7 & \pm 15.0 \\
\hline pH & 6.449 & \pm 0.063 & 6.462 & \pm 0.099 & 6.121 & \pm 0.102 \\
\hline $\mathrm{K}_{\mathrm{sp}, \mathrm{i}} / \mathrm{K}_{\mathrm{sp}, \mathrm{f}}$ & 2.981 & \pm 0.264 & 1.213 & \pm 0.226 & 0.700 & \pm 0.1 \\
\hline
\end{tabular}

Values are given as mean \pm SEM. Group I consisted of patients with idiopathic hypercalciuria, group II, patients with recurrent calcium-containing stones and normocalciuria, and group III subjects without nephrolithiasis. Urines of group I were markedly supersaturated with respect to brushite $\left(\mathrm{K}_{\mathbf{s p}, \mathrm{i}} / \mathrm{K}_{\mathrm{sp}, \mathrm{f}}\right.$ greater than $\left.\mathbf{1}\right)$.

Materials. The urine specimens were the same as those reported previously (11) and consisted of 37 24-hr specimens from 15 patients with idiopathic hypercalciuria (group I) (20), 22 specimens from nine patients with recurrent calcium-containing renal stones with normal urinary calcium (group II), and 21 specimens from 19 subjects with normal urinary calcium and without nephrolithiasis (group III). The mean age of patients in group I was $45 \mathrm{yr}$, in group II, $46 \mathrm{yr}$, and in group III, 38 yr. There were 11 men and 4 women in group I, five men and four women in group II, and eight men and 11 women in Group III. The patients in groups I and II had passed multiple renal calculi consisting of pure calcium phosphate, or mixed calcium phosphate and oxalate, as shown by X-ray diffraction. All patients in group II gave history of urinary tract infection during the course of their disease. All the patients studied had normal serum calcium values, and none presented any evidence of bone disease. These patients had received a diet containing each day $400-600 \mathrm{mg}$ of calcium and approximately $1000 \mathrm{mg}$ of phosphorus for 5 or more days before and during urine collection. The specimens were collected in plastic containers at $10^{\circ} \mathrm{C}$ without preservative; those with $\mathrm{pH}$ greater than 6.70 were preserved under oil. None of the specimens studied showed visible precipitation.

After the specimens had been warmed to $37^{\circ} \mathrm{C}$ in a water bath, the $\mathrm{pH}$ was measured in a Beckman expanded scale $\mathrm{pH}$ meter to the nearest 0.005 units. The $\mathrm{pH}$ meter was standardized with Fisher $\mathrm{pH}$ buffer $\left(\mathrm{pH} 6.960\right.$ at $37^{\circ} \mathrm{C}$ ) which was prepared according to National Bureau of Standards specifications.

Chemical determinations. The concentration of following substances was measured on all urine specimens: sodium, potassium, ammonium, magnesium, calcium, and orthophosphate $(\mathrm{P})$. Sodium and potassium were determined by flame photometry and ammonium by the Conway microdiffusion method (30). Magnesium was measured in an atomic absorption spectrophotometer (Instrumentation Laboratory Inc., Watertown, Mass.). Calcium was determined by the method of Fiske and Logan (31), and P by the method of Fiske and SubbaRow (32). On selected urines, sulfate and chloride were also measured by the gravimetric method of Folin (33) and by a chloride titrator (Aminco Cotlove, American Instrument Co., Inc., Silver Spring, Md), respectively (34).

Incubation of urine specimens in brushite. $200 \mathrm{mg}$ of brushite (Mallinckrodt Chemical Works, St. Louis, Mo., CaHPO ${ }_{4} \cdot 2 \mathrm{H}_{2} \mathrm{O}$,

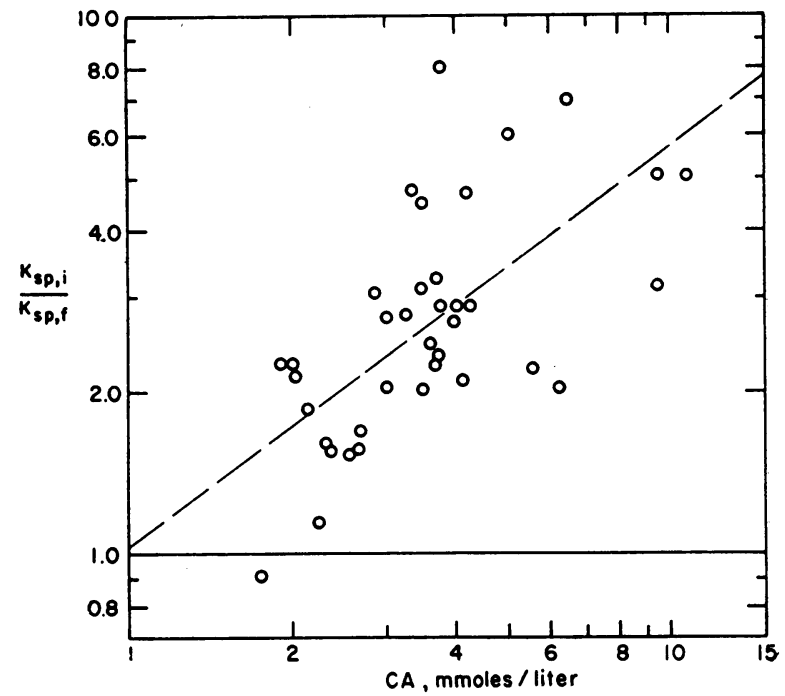

FIGURE 2 Dependence of activity product ratio $\left(\mathrm{K}_{\mathrm{sp}, \mathrm{i}} / \mathrm{K}_{\mathrm{sp}, \mathrm{f}}\right)$ on calcium concentration of urines from patients with idiopathic hypercalciuria. The horizontal line at $\mathrm{K}_{\mathrm{sp}, \mathrm{i}} / \mathrm{K}_{\mathrm{sp}, \mathrm{f}}$ of 1.0 represents the state of saturation with respect to brushite. The values above this line estimates the number of times the urine is supersaturated. The correlation coefficient was 0.635 .

calcium-to-phosphorus molar ratio of 1.0$)^{8}$ were kept in suspension in $100 \mathrm{ml}$ of urine with a magnetic stirrer for 3-4 days at $37^{\circ} \mathrm{C}(35,36) .0 .5 \mathrm{ml}$ of chloroform was added to the suspension to control bacterial growth. The supernatant was obtained by centrifugation of the suspension at $1400 \mathrm{~g}$ for $30 \mathrm{~min}$. The supernatant was measured for concentrations of $\mathrm{Na}, \mathrm{K}, \mathrm{NH}_{4}, \mathrm{Mg}, \mathrm{Ca}$, and $\mathrm{P}$ and for $\mathrm{pH}$. Under these conditions, multiple determinations of $K_{\mathrm{sp}}$ from the same urine specimen varied by less than $5 \%$. In one undersaturated and in one supersaturated urine specimen, the amount of brushite and the period of incubation were varied. These studies showed that a variation in solid-to-solution ratio (milligrams of brushite to milliliters of urine) from 1.0 to 10 or the period of incubation from 2 to 10 days did not significantly alter the activity product of the urine supernatant.

\section{RESULTS}

Comparison of the three groups. As reported previously (11), the activity product ratio $\left(\mathrm{K}_{\mathrm{sp}, \mathrm{1}} / \mathrm{K}_{\mathrm{ep}, \mathrm{s}}\right)$ of urine from patients with idiopathic hypercalciuria (group I) was significantly greater than that of the other two groups (Table IV). The urine from group I patients was clearly supersaturated with respect to brushite. This was a result mainly of the high urinary excretion of calcium, since $[\mathrm{P}]$, total volume of urine (TV), and $\mathrm{pH}$ in group I patients were only slightly higher or not significantly different from those of the other groups. Indeed. a good correlation (correlation coefficient of 0.635 ) was shown between log of activity

${ }^{3}$ This preparation gave $\mathrm{X}$-ray diffraction pattern characteristic of brushite. X-ray diffraction was kindly performed by Dr. C. Skinner of Yale University. 


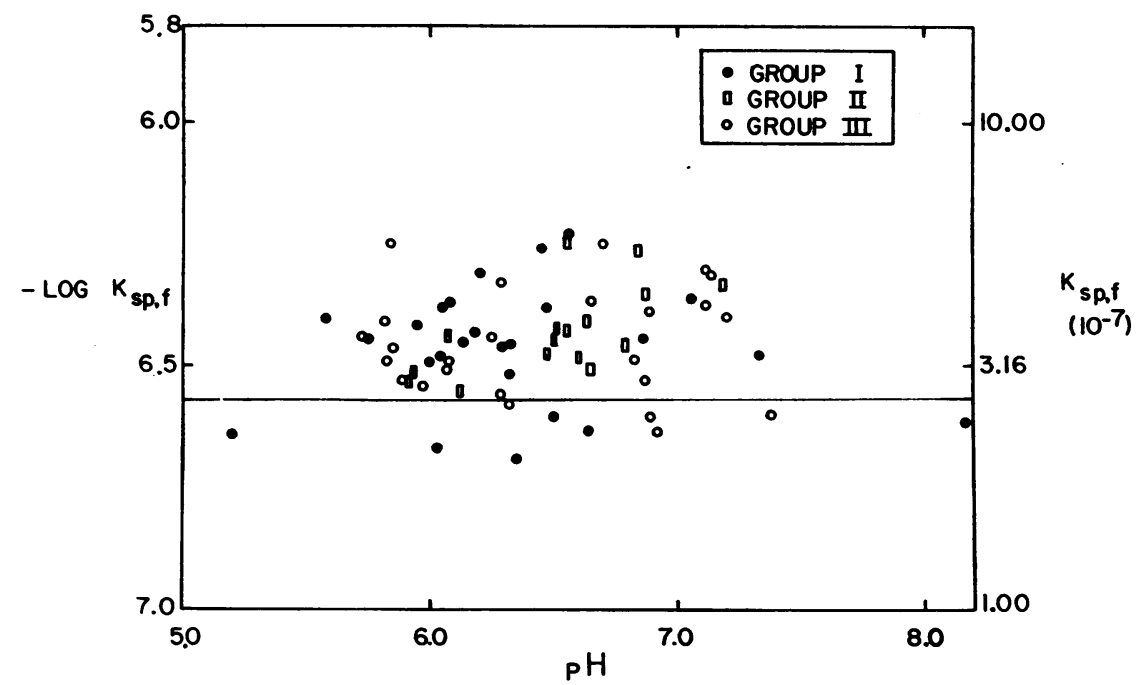

FIgURE 3. Comparison of $K_{\mathrm{sp}, \mathrm{f}}$ between three groups. The activity product of urines after incubation with brushite $\left(\mathrm{K}_{\mathrm{ep}, \mathrm{f}}\right)$ was generally greater than the theoretical activity of brushite $\left(\mathrm{K}_{\mathrm{sp} \text {, th }}=2.68 \times 10^{-7}\right.$, represented by the horizontal line in the figure $)$. There was no significant difference in $K_{8 p, f}$ among the three groups. $K_{8 p, f}$ was $3.57 \pm 0.19 \times 10^{-7}$ (SEM) in group I, $3.82 \pm 0.22 \times 10^{-7}$ in group II, and $3.67 \pm 0.19 \times 10^{-7}$ in group III.

product ratio and $\log$ of calcium concentration in the urines from group I (Fig. 2).

Effect of incubation with brushite on chemical composition of urine. The chemical composition of supersaturated urine specimens from the three groups was compared with that of undersaturated urine before and after incubation with brushite (Table III). The mean activity product ratio of the supersaturated urine was 2.441 as compared with 0.490 for the undersaturated urine. With the supersaturated urine, there was a fall in $\left[\mathrm{Ca}^{++}\right]$and $[\mathrm{P}]$ upon incubation with brushite, corresponding to an incorporation into the solid phase of 1.08 mmoles of $\mathrm{Ca}$ and 1.21 mmoles of $\mathrm{P}$ per liter of urine. With the undersaturated urine there was an increase in both $\left[\mathrm{Ca}^{++}\right]$and $[\mathrm{P}]$ in solutions as incubation progressed; this finding indicates partial dissolution of brushite.

Activity product of urine after incubation with brushite $\left(K_{e p, r}\right)$. The activity product of $\mathrm{Ca}^{++}$and $\mathrm{HPO}_{4}=$ after incubation with brushite $\left(K_{\mathrm{sp}, \mathrm{f}}\right)$ was greater than the theoretical activity product of brushite $\left(\mathrm{K}_{\mathrm{sp}, \mathrm{th}}\right)$ of $2.68 \times 10^{-7}$ (reference 18 , footnote 2 ), due probably to the presence of various ligands for $\mathrm{Ca}^{++}$and $\mathrm{HPO}_{4}=$ in urine, such as sulfate and citrate ions. ${ }^{2} \mathrm{~K}_{\mathrm{sp}, \mathrm{r}}$ ranged from 2.04 to $5.95 \times 10^{-7}$, or approximately twofold the value of Kap,th (Fig. 3). However, there was no significant difference in $\mathrm{K}_{\mathrm{sp}, \mathrm{r}}$ among the three groups. The mean value for $K_{\text {ap, }}$ was approximately $40 \%$ greater than $\mathrm{K}_{\mathrm{ep}, \mathrm{th}}$ in the patients with idiopathic hypercalciuria and in those with normal urinary calcium (groups II and III).

\section{DISCUSSION}

Several theories have been invoked for the pathogenesis of calcium-containing renal calculus. The precipitationcrystallization theory considers stone formation as a physicochemical process of precipitation of calcium salts from a supersaturated solution (5-8). In the matrix theory, the stone develops by the process of nucleation and crystal growth in an organic matrix (1-4). Although convincing experimental evidence may be lacking, nucleation can theoretically occur in an organic matrix from an undersaturated solution. In the matrix-inhibitor theory, certain polypeptides or pyrophosphates may prevent stone formation by inhibiting nucleation $(1,2,37-39)$. These inhibitors may prevent nucleation from a supersaturated solution.

The subsequent development of a stone from the nucleus is probably governed by the physicochemical solubility of the mineral phase of the stone. Thus the crystal nidus, formed either by precipitation or under the influence of an organic matrix, probably cannot grow into a stone unless the urine is supersaturated $(8,11)$. In an undersaturated urine, the crystal nidus would be unstable and would probably undergo dissolution. An essential requirement for the pathogenesis of renal calculus, irrespective of the mechanism, is therefore a state of supersaturation of the urine in terms of the constituent ions of the stone.

The initial nidus of calcium-containing renal calculus is believed to be composed of calcium phosphate (40). Several workers have considered octacalcium 
phosphate or amorphous calcium phosphate as the phase which controls the development of calcium phosphate stone $^{4}$ (17). However, a renal calculus of octacalcium phosphate is seldom if ever found (41), and the calcium phosphate precipitated from urine in vitro is never octacalcium phosphate. ${ }^{2}$ Further, octacalcium phosphate is unstable in the normal acid $\mathrm{pH}$ of urine; therefore, it is unlikely to be the phase governing calcium phosphate stone formation at $\mathrm{pH}$ less than 7 . Although amorphous calcium phosphate may be formed by rapid precipitation from a highly supersaturated solution of alkaline $\mathrm{pH}(42,43)$, it is not known whether this phase can develop in the usual acid $\mathrm{pH}$ of urine. Even if the amorphous calcium phosphate constitutes the crystal nidus, it is rapidly transformed to other calcium phosphates. The latter, more stable calcium phosphates, rather than the amorphous calcium phosphate, probably controls crystal growth or the development of a macroscopic stone. Finally, it is difficult or impossible to calculate the degree of saturation of urine with respect to octacalcium phosphate or amorphous calcium phosphate. Although the activity product of octacalcium phosphate has been calculated for urine (17), it was not compared with the activity product of the supernatant of urine which had been incubated with octacalcium phosphate. Therefore, it is subject to the errors attendant in the calculation of activity product, such as in the determination of the activity coefficients of constituent ions and of the stability constants of various complexes in urine (see Methods, section F) ; hence, it may not give an accurate measure of the degree of saturation of urine. The solubility of amorphous calcium phosphate is not known, although it is believed to be greater than that of hydroxyapatite.

In contrast, we consider brushite as the mineral phase which probably constitutes the initial nidus and which governs the subsequent development of renal stone of calcium phosphate composition (11). As in the artificial solution of calcium and phosphate (18), the calcium phosphate precipitated from urine of acid $\mathrm{pH}$ is brushite. ${ }^{2}$ Brushite is relatively stable below $\mathrm{pH}$ 6.9. At $\mathrm{pH}$ greater than 6.9, brushite is transformed into calcium phosphates of higher calcium-to-phosphorus molar ratio $(\mathrm{Ca} / \mathrm{P})$ (18) ; however, the initial calcium phosphate precipitated has $\mathrm{Ca} / \mathrm{P}$ of approximately 1 , a fact suggesting that brushite is formed first (19). Further, brushite is a constituent of stone (41), and its solubility in urine is not difficult to calculate $(11,25)$.

It was possible to estimate the degree of saturation of urine with respect to brushite by calculating the activity product of $\mathrm{Ca}^{++}$and $\mathrm{HPO}_{4}=$ in urine, if the effect of $\mathrm{pH}$ and ionic strength on the dissociation of $\mathrm{H}_{2} \mathrm{PO}_{4}^{-}$ and the effect of ionic strength on the activity coeffi-

\footnotetext{
'Thomas, W. E. 1968. Personal communication.
}

cients of $\mathrm{Ca}^{++}$and phosphate ions are taken into consideration. It should be emphasized that the physicochemical solubility should be expressed as activity products and not as concentration products (25). The solubility expressed in terms of ionic activity is independent of ionic strength, $\mathrm{pH}$, and temperature, unlike the concentration product. It should be obvious that the ratio of activity products of $\mathrm{Ca}^{++}$and $\mathrm{HPO}_{4}=$ of urine before and after incubation with brushite is not equivalent to that obtained from concentration products, unless $\mathrm{pH}$ and ionic strength do not change with incubation. That situation seldom, if ever, occurs.

In our calculation of the activity product of brushite, the complexed forms of $\mathrm{Ca}^{++}$and $\mathrm{HPO}^{+}=$were not excluded. This calculation therefore gave an overestimation of the true solubility of brushite involving only the free ions. This error was removed by obtaining the ratio of the activity products of urine before and after incubation with synthetic brushite (see Methods, section F).

From these considerations, it is clear that a state of saturation of urine with respect to brushite is one of the important determinants of calcium phosphate stone formation. A state of supersaturation of urine is essential for the formation of a nidus of brushite, irrespective of the model for stone formation (17).

It should be emphasized that a renal calculus need not form despite the passage of persistently supersaturated urine because of the presence of "inhibitors" in urine (1, 2, 37-39). These inhibitors, believed to be polypeptides $(1,2,39)$ or pyrophosphates $(37,38)$, probably interfere with crystal nidus formation. However, it is unlikely that the inhibitors significantly influence the growth and dissolution of an already formed calcium phosphate stone, because they occur in very low concentrations. This conclusion is supported by our finding that the solubility of brushite $\left(K_{s p, r}\right)$ in the urine of stone formers is similar to that in the urine of normal subjects (Fig. 3). It is thought that these inhibitors occur in higher concentrations in normal urine that in urines from stone formers. If they influence the solubility of calcium phosphate, the $K_{s p, r}$ in the urines of normal subjects should be different from that of urines of stone formers.

It is unfortunate that these studies of inhibition were performed with altered urine specimens (which were adjusted to same $\mathrm{pH}$ and specific gravity) and without precise determination of the degree of saturation of urine with respect to brushite or other solid phase. The role of the inhibitors should be reexamined in terms of the state of saturation of urine. Such a study should allow quantitation of inhibition, as well as test the validity of the model proposed, wherein brushite plays a regulatory role. 
We now consider two reservations against our hypothesis of renal stone formation, wherein brushite plays a regulatory role.

First, brushite stones occur infrequently (41). This fact probably reflects the hydrolysis of brushite to compounds of higher $\mathrm{Ca} / \mathrm{P}$ ratio, which occurs very slowly in acid $\mathrm{pH}$ but rapidly in alkaline $\mathrm{pH}(18,19)$. The preponderance of renal stones of higher ratio $\mathrm{Ca} / \mathrm{P}$ compounds is not surprising, since the passage of alkaline urine during the course of the stone disease is not uncommon. Even if hydroxyapatite or tricalcium phosphate were the only phase present in stone, the degree of saturation of urine with respect to brushite probably controls the growth of stone. Because of the relatively high solubility of brushite $(17,36)$, the urine which is supersaturated with respect to brushite should also be supersaturated with respect to other calcium phosphates.

Second, our hypothesis pertains strictly to the formation of renal stone of calcium phosphate and not calcium oxalate. However, the initial nidus of all calciumcontaining renal stones is usually calcium phosphate (40). The deposition of calcium oxalate, calcium phosphate, or both occurs over the nidus. The prevention of the formation of calcium phosphate nidus may thus avert the development of stone of calcium oxalate as well as that of calcium phosphate. This concept in fact forms the basis for the inhibition studies, based on calcification (with calcium phosphate) of rachitic cartilage $(1,2)$.

We conclude that among patients with idiopathic hypercalciuria the passage of a urine supersaturated with respect to brushite accounts for the formation of calcium phosphate stones and may account for the occurrence of calcium oxalate stones. Further, we believe that a renal stone may form at any $\mathrm{pH}$ of urine, since the urine specimens of these patients were generally supersaturated at both acid and basic $\mathrm{pH}$ (11), due to the excessive excretion of calcium (Fig. 2).

Among normocalciuric subjects, our results suggest that persistent passage of urine of high $\mathrm{pH}$ plays an important role in the development of renal stone, since supersaturation with respect to brushite was usually seen at $\mathrm{pH}$ greater than 6.5 (11). Indeed, nephrolithiasis of calcium phosphate composition is not uncommon in normocalciuric subjects who consistently excrete urine of high $\mathrm{pH}$ because of infection with urea-splitting organisms or because of treatment with alkali. All nine normocalciuric patients with renal stones in this study gave history of urinary tract infection during the course of their disease.

The absence of renal stone formation among normal subjects who excrete supersaturated urine may be due to the inhibition of nucleation. In addition, since their urinary $\mathrm{pH}$ is not consistently alkaline, the nidus for stone is less likely to be established.

In conclusion, it is proposed that a state of supersaturation with respect to brushite is essential for the development of renal calculus of calcium phosphate origin. In this schema for the pathogenesis of renal calculi, brushite is considered to constitute the nidus and to regulate the subsequent growth of the nidus into a stone. Inhibitors of nucleation in urine may influence the development of the initial nidus from a supersaturated urine. However, it should be appreciated that a stone cannot form from an undersaturated urine, irrespective of these inhibitors. One of the aims of the treatment of renal stone disease should therefore be a conversion of urine from a state of supersaturation to one of undersaturation. An important aspect of this study is that it makes possible a quantitative evaluation of various measures for the treatment or prevention of nephrolithiasis of calcium phosphate composition.

\section{REFERENCES}

1. Howard, J. E., W. C. Thomas, L. M. Barker, L. H. Smith, and C. L. Wadkins. 1967. The recognition and isolation from urine and serum of a peptide inhibitor to calcification. Johns Hopkins Med. J. 120: 119.

2. Thomas, W. C., and J. E. Howard. 1959. Studies on the mineralizing propensity of urine from patients with and without renal calculi. Trans. Ass. Amer. Physicians (Philadelphia). 72: 181.

3. Boyce, W. H., and J. S. King, Jr. 1963. Present concepts concerning the origin of matrix and stones. Ann. N. Y. Acad. Sci. 104: 563.

4. Boyce, W. H. 1968. Organic matrix of human urinary concretions. Amer. J. Med. 45: 673.

5. Vermeulen, C. W., E. S. Lyon, and W. B. Gill. 1964. Artificial urinary concretions. Invest. Urol. 1: 370.

6. Vermeulen, C. W., E. S. Lyon, and F. A. Fried. 1965. On the nature of the stone-forming process. J. Urol. 94: 176.

7. Elliot, J. S. 1965. Urinary calculus disease. Surg. Clin. N. Amer. 45: 1393 .

8. Vermeulen, C. W., and E. S. Lyon. 1968. Mechanisms of genesis and growth of calculi. Amer. J. Med. 45: 684 .

9. Neuman, W. F., and M. W. Neuman. 1958. The chemical dynamics of bone mineral. University of Chicago Press, Chicago. 169.

10. MacGregor, J., W. G. Robertson, and B. E. C. Nordin. 1965. Octacalcium phosphate: the phase governing the solubility equilibrium in apatitic calculi. Brit. J. Urol. $37: 518$.

11. Pak, C. Y. C., E. C. Diller, G. W. Smith II, and E. S Howe. 1969. Renal stones of calcium phosphate: physiochemical basis for their formation. Proc. Soc. Exp. Biol. Med. 130: 753 .

12. Andrews, J. C., C. L. Yarbro, R. L. Golby, and I. T. Sell. 1955. Studies on the mechanism of formation of renal calculi. I. J. Urol. 73: 930.

13. Vermeulen, C. W., E. S. Lyon, and G. H. Miller. 1958. Calcium phosphate solubility in urine as measured by a 
precipitation test: experimental urolithiasis. XIII. J. Urol. 79: 596.

14. Fleisch, H. 1965. Some new concepts on the pathogenesis and treatment of urolithiasis. Urol. Int. 19: 372.

15. Elliot, J. S. 1957. Calcium phosphate solubility in urine. J. Urol. $77: 269$.

16. Nordin, B. E. C., and W. G. Robertson. 1966. Calcium phosphate and oxalate ion-products in normal and stoneforming urines. Brit. Med. J. 1: 450.

17. Robertson, W. G., M. Peacock, and B. E. C. Nordin. 1968. Activity products in stone-forming and non-stoneforming urine. Clin. Sci. 34: 579.

18. Strates, B. S., W. F. Neuman, and G. J. Levinskas. 1957. The solubility of bone mineral. II. Precipitation of nearneutral solutions of calcium and phosphate. J. Phys. Chem. 61: 279.

19. Neuman, W. F., T. Y. Toribara, and B. J. Mulryan, 1962. Synthetic hydroxyapatite crystals. I. Sodium and potassium fixation. Arch. Biochem. Biophys. 98: 384.

20. Henneman, P. H., P. H. Benedict, A. P. Forbes, and H. R. Dudley. 1958. Idiopathic hypercalcuria. N. Engl. J. Med. 259: 802 .

21. Daniels, F., and R. A. Alberty. 1961. Physical Chemistry. John Wiley \& Sons, Inc., New York. 2nd edition. 156.

22. Moreno, E. C., T. M. Gregory, and W. E. Brown. 1966. Solubility of $\mathrm{CaHPO}_{4} \cdot 2 \mathrm{H}_{2} \mathrm{O}$ and formation of ion pairs in the system $\mathrm{Ca}(\mathrm{OH})_{2}-\mathrm{H}_{8} \mathrm{PO}_{4}^{-} \mathrm{H}_{2} \mathrm{O}$ at $37.5^{\circ} \mathrm{C}$. I. Res. Nat. Bur. Stand. 70A : 545.

23. Frankenthal, R. P. 1963. Activity coefficients. In Handbook of Analytical Chemistry. McGraw-Hill Book Company, New York. 1st edition. 1-6.

24. Schwartz, W. B., N. Bank, and R. W. P. Cutler. 1959. The influence of urinary ionic strength on phosphate $\mathrm{pK}_{2}{ }^{\prime}$ and the determination of titratable acid. J. Clin. Invest. $38: 347$.

25. Levinskas, G. 1953. Solubility studies of synthetic hydroxyapatite (the lattice of bone mineral). Doctoral thesis. University of Rochester, Rochester, N. Y.

26. Nims, L. F. 1933. The second dissociation constant of phosphoric acid from $20^{\circ}$ to $50^{\circ}$. J. Amer. Chem. Soc. 55: 1946.

27. MacInnes, D. A. 1919. The activities of ions of strong electrolytes. J. Amer. Chem. Soc. 41: 1086.

28. Harned, H. S., and B. B. Owen. 1950. The Physical Chemistry of Electrolytic Solutions. Reinhold Publishing Corp., New York. 2nd edition.
29. Stokes. J. M. 1945. The osmostic and activity coefficients of sodium and potassium dihydrogen phosphate at $25^{\circ}$. Trans. Faraday Soc. 41: 685.

30. Conway, E. J. 1950. Microdiffusion Analysis and Volumetric Error. Crosby Lockwood \& Sons Ltd., London.

31. Fiske, C. H., and M. A. Logan. 1931. Determination of calcium by alkalimetric titration. II. The precipitation of calcium in the presence of magnesium, phosphate and sulfate, with application to the analysis of urine. J. Biol. Chem. 93: 211 .

32. Fiske, C. H., and Y. SubbaRow. 1925. The colorimetric determination of phosphorus. J. Biol. Chem. 66: 375.

33. Peters, J. P., and D. D. van Slyke. 1932. Quantitative Clinical Chemistry. Williams \& Wilkins Co., Baltimore. 2: 890 .

34. Cotlove, E., H. V. Trantham, and R. L. Bowman. 1958. An instrument and method for automatic, rapid, accurate, and sensitive titration of chloride in biologic samples. J. Lab. Clin. Med. 51: 461.

35. Pak, C. Y. C., and F. C. Bartter. 1967. Ionic interaction with bone mineral. I. Evidence for an isoionic calcium exchange with hydroxyapatite. Biochim. Biophys. Acta. 141: 401.

36. Pak, C. Y. C., and H. C. W. Skinner. 1968. Ionic interaction with bone mineral. IV. Varying affinity of synthetic calcium phosphates for $\mathrm{Ca}^{2+}$. Biochim. Biophys. Acta. $165: 274$.

37. Fleisch, H., and S. Bisaz. 1962. Isolation from urine of pyrophosphate, a calcification inhibitor. Amer. J. Physiol. 203: 671 .

38. Fleisch, H., S. Bisaz, and A. D. Care. 1964. Effect of orthophosphate on urinary pyrophosphate excretion and the prevention of urolithiasis. Lancet. 1: 1065.

39. Howard, J. E., and W. C. Thomas, Jr. 1968. Control of crystallization in urine. Amer. J. Med. 45: 693.

40. Prien, E. L. 1955. Studies in urolithiasis. III. Physicochemical principles in stone formation and prevention. J. Urol. 73: 627.

41. Prien, E. L., and E. L. Prien, Jr. 1968. Composition and structure of urinary stone. Amer. J. Med. 45: 654 .

42. Eanes, E. D., and A. S. Posner. 1968. Intermediate phases in the basic solution preparation of alkaline earth phosphates. Calcified Tissue Res. 2: 38.

43. Fleisch, H., R. G. G. Russell, and S. Bisaz. 1968. Influence of pyrophosphate on the transformation of amorphous to crystalline calcium phosphate. Calcified Tissue Res. 2: 49. 